\title{
Cytoarchitecture and musculotopic organization of the facial motor nucleus in Cebus apella monkey
}

\author{
J. A. C. Horta-Júnior, ${ }^{1}$ O. J. Tamega ${ }^{1}$ and R. J. Cruz-Rizzolo ${ }^{2}$ \\ ${ }^{1}$ Department of Anatomy, Institute of Biosciences, São Paulo State University, Botucatu, São Paulo, Brazil \\ ${ }^{2}$ Department of Basic Sciences, School of Dentistry, São Paulo State University, Araçatuba, São Paulo, Brazil
}

\begin{abstract}
The architecture and musculotopic organization of the facial motor nucleus in the Cebus apella monkey (a New World primate) were investigated using histological techniques and a multiple labelling strategy, in which horseradish peroxidase-conjugated neuroanatomical tracers (CTB-HRP and WGA-HRP) and fluorescent tracers were injected into individual facial muscles. The facial motor nucleus was formed by multipolar motoneurons and had an ovoid shape, with its rostrocaudal axis measuring on average $1875 \mu \mathrm{m}$. We divided the nucleus into four different subnuclei: medial, intermediate, dorsal and lateral. Retrograde labelling patterns revealed that individual muscles were innervated by longitudinal functional columns of motoneurons. The columns of the orbicularis oculi, zygomaticus, orbicularis oris, auricularis superior, buccinator and platysma muscles were located in the dorsal, intermediate, lateral, medial, lateral and intermediate subnuclei, respectively. However, the motoneuron columns of the levator labii superioris alaeque nasi muscle and frontalis muscle could not be associated with a specific subnucleus. The present results confirm previous studies regarding the musculotopic organization of the facial motor nucleus. However, we observed some particularities in terms of the relative size of each column in C. apella, which might be related to the functional and behavioral importance of each muscle in the particular context of this primate.
\end{abstract}

Key words CTB-HRP; facial muscles; motoneurons; neuroanatomical tracers; primate.

\section{Introduction}

Facial expression is one of the most important forms of communication observed in primates, and is associated with the ability to vocalize and gesticulate and is supported by a delicate cutaneous musculature innervated by the facial nerve (Weigel, 1979). The facial motor nucleus (7Mot) is the source of nervous impulses to the musculature of facial expression. In primates, the neuronal organization of the 7Mot is only partially known.

The cytoarchitectonic division of the 7Mot and the representation of the facial nerve branches and muscles of facial expression within this nucleus have been studied in various non-primate species: opossum (Provis, 1977), cat (Kume et al. 1978), mouse (Ashwell, 1982), bat (Friauf \& Herbert, 1985), rabbit (Baisden et al. 1987) and rat (Tsai

\footnotetext{
Correspondence

Professor Dr Roelf J. Cruz Rizzolo, Department of Basic Sciences - School of Dentistry, São Paulo State University - UNESP, R. José Bonifácio 1193, Araçatuba - SP, 16015-100 - Brazil. T: 5518 6203308; F: 5518 6203332; E: roelf@foa.unesp.br

Accepted for publication 4 December 2003
}

et al. 1993). The musculotopic organization of the 7 Mot has been investigated using different techniques, such as identification of anterograde degeneration of the neuromuscular junction after introducing small lesions in the 7Mot (Szentágothai, 1948), identification of retrograde degeneration induced in different portions of the nucleus after sectioning the branches of the facial nerve (Courville, 1966; Dom et al. 1973), determination of cholinesterase activity after selective sectioning of the facial nerve peripheral branches (Dom et al. 1973), and antidromic activation (Martin \& Lodge, 1977). The use of retrograde tracers has provided a more precise picture regarding the subdivisions of the 7 Mot and the nuclear representation of the facial musculature (Ashwell, 1982; Shohara \& Sakai, 1983; Hinrichsen \& Watson, 1984; Friauf \& Herbert, 1985; Shaw \& Baker, 1985; Friauf, 1986; Semba \& Egger, 1986; Baisden et al. 1987; Jenny \& Saper, 1987; Satoda et al. 1987, 1988; Welt \& Abbs, 1990; Tsai et al. 1993). However, divergent results regarding the number and delimitation of the subnuclei or regarding the correlation between 'functional' and architectonic subnuclei have been reported (Jenny \& Saper, 1987; 
Satoda et al. 1987; Costa-Llobet et al. 1988; Welt \& Abbs, 1990; Tsai et al. 1993). One factor that might explain this discordance is the experimental approach used in some of these studies, which was mainly based on the lesion or injection of neuroanatomical tracers into the motor branches of the facial nerve and not directly into the different facial muscles. According to Hinrichsen \& Watson (1984), this method might impose an artificial musculotopic organization. This assumption is supported by studies showing that nerve fibres inside the branches of the facial nerve originate from more than one subnucleus (Jenny \& Saper, 1987; Satoda et al. 1987; Tsai et al. 1993) and that the muscles of facial expression are innervated by more than one branch of the facial nerve (Oliveira et al. 1988).

The musculotopic organization of the 7Mot of primates has been studied in Old World monkeys only (Jenny \& Saper, 1987; Satoda et al. 1987; Welt \& Abbs, 1990). Thus, new investigations involving other primate genera are necessary to provide a more complete comparative basis. No literature regarding the musculotopic organization of the 7Mot in New World monkeys is available thus far. The evolutionary history of this group of primates is still unclear and subject to disagreement, but it has been accepted that they have evolved independently from Old World monkeys over a period of 35 million years (Ciochon \& Chiarelli, 1980; Goodman et al. 1998; Schneider et al. 2001). The effect of this parallel evolution on the organization of neural systems remains unclear and therefore studies on the neural organization of $\mathrm{New}$ World primates are needed. Capuchin monkeys (Cebus apella) are a good experimental model because they belong to the group of New World monkeys and show a very rich repertoire of vocalization and facial expression (Weigel, 1979).

Therefore, the objective of the present investigation was to analyse the cytoarchitecture and musculotopic organization of the 7Mot of capuchin monkeys by histological staining techniques and retrograde transport of neuroanatomical tracers injected directly into the muscles of facial expression.

\section{Materials and methods}

\section{Animals}

Seven young adult male capuchin monkeys weighing 2255-2790 g were obtained from the Capuchin Monkey (Cebus apella) Reproduction Center, Department of Basic
Sciences, School of Dentistry, São Paulo State University 'Júlio de Mesquita Filho' - UNESP, Araçatuba, SP, Brazil, in accordance with the Brazilian Institute for the Protection of the Environment (IBAMA). The animals were housed in a group in a vivarium, with water and food available ad libitum. Experimental procedures were conducted according to the Guidelines for the Care and Use of Mammals in Neuroscience and Behavioral Research (Committee on Guidelines for the Use of Animals in Neuroscience \& Behavioral Research, 2003), and approved by the local laboratory animal care and use committee.

\section{Injection of neuroanatomical tracers}

For neuroanatomical tracer injections, five animals were anesthetized by intraperitoneal (i.p.) administration of $30 \mathrm{mg} \mathrm{kg}^{-1}$ sodium thiopental. After detailed study of the anatomical organization of the C. apella facial muscles, these muscles were delimited with a dermatographic pencil, indicating the injection sites. Multiple tracer injections of $2 \mu \mathrm{L}$ were made in each muscle with a Hamilton syringe. This minimally invasive procedure, standardized by Hinrichsen \& Watson (1984) and Welt \& Abbs (1990), provides a more precise representation of each muscle inside the 7 Mot. The total amount of tracer injected varied according to the type of tracer and muscle analysed. Table 1 summarizes the characteristics of each experiment and survival times.

The retrograde tracer preferentially used was horseradish peroxidase conjugated with cholera toxin $B$ subunit (CTB-HRP; List Biological Laboratories, Inc. \#105). This tracer was chosen because of its high sensitivity even when applied in small volumes, which prevents contamination of neighboring structures (Trojanowski et al. 1982; Wan et al. 1982). The wheat germ agglutininHRP conjugate (WGA-HRP, Sigma \#L7017) possesses properties similar to CTB-HRP and was used in one case. In two cases, multiple labelling experiments were carried out using the fluorescent tracers Diamidino yellow (Sigma \#D0281) and Fast blue (Sigma \#F5756), which were injected 13 days before the HRP conjugates. The aim of these experiments was to confirm the musculotopic organization and to determine the existence of doublelabelled motoneurons.

Because the 7Mot innervates ipsilaterally the muscles of facial expression (Jenny \& Saper, 1987; Satoda et al. 1987; Welt \& Abbs, 1990) on each side of the animal's face corresponded to a different experiment, thus reducing the number of animals used in this study. 
Table 1 Summary of tracer injection in each retrograde axonal transport experiment

\begin{tabular}{|c|c|c|c|c|c|}
\hline Animal & Side & $\begin{array}{l}\text { Neuroanatomical } \\
\text { tracer }\end{array}$ & $\begin{array}{l}\text { Survival } \\
\text { (days) }\end{array}$ & Muscle & $\begin{array}{l}\text { Total } \\
\text { volume }(\mu \mathrm{L})\end{array}$ \\
\hline \multirow[t]{6}{*}{ M8 } & Left & DY & 15 & orbicularis oris (superior portion) & 20 \\
\hline & & $\mathrm{FB}$ & 15 & platysma & 40 \\
\hline & & CTB-HRP & 2 & orbicularis oculi (superior portion) & 30 \\
\hline & Right & DY & 15 & frontalis & 20 \\
\hline & & $\mathrm{FB}$ & 15 & LELSAN & 20 \\
\hline & & CTB-HRP & 2 & auricularis superior & 40 \\
\hline \multirow[t]{6}{*}{ M9 } & Left & $\mathrm{FB}$ & 15 & orbicularis oculi (superior portion) & 40 \\
\hline & & DY & 15 & buccinator & 25 \\
\hline & & WGA-HRP + HRP & 2 & zygomaticus & 30 \\
\hline & Right & $\mathrm{FB}$ & 15 & orbicularis oris (inferior portion) & 40 \\
\hline & & DY & 15 & zygomaticus & 40 \\
\hline & & WGA-HRP & 2 & orbicularis oculi (inferior portion) & 30 \\
\hline \multirow[t]{2}{*}{ M11 } & Left & $\mathrm{CTB}-\mathrm{HRP}+\mathrm{HRP}$ & 2 & LELSAN & 20 \\
\hline & Right & $\mathrm{CTB}-\mathrm{HRP}+\mathrm{HRP}$ & 2 & orbicularis oris & 40 \\
\hline \multirow[t]{2}{*}{ M12 } & Left & CTB-HRP & 2 & frontalis & 55 \\
\hline & Right & CTB-HRP & 2 & buccinator & 45 \\
\hline \multirow[t]{2}{*}{ M14 } & Left & CTB-HRP & 2 & platysma & 50 \\
\hline & Right & CTB-HRP & 2 & frontalis & 20 \\
\hline
\end{tabular}

\section{Tissue processing}

Forty-eight hours after injection of both HRP conjugates, the animals were deeply anesthetized with sodium thiopental (45 $\mathrm{mg} \mathrm{kg}^{-1}$, i.p.) and perfused through the heart with $0.9 \%$ saline, followed by perfusion of the fixative and, finally, $5 \%$ glycerol solution at $4{ }^{\circ} \mathrm{C}$. In the HRP experiments, $2.5 \%$ glutaraldehyde and $1 \%$ paraformaldehyde were used as fixative, whereas in the fluorescent tracer experiments $1.5 \%$ paraformaldehyde and $0.5 \%$ glutaraldehyde were used as fixative (Cavada et al. 1984). In both cases, all solutions were prepared in $0.1 \mathrm{~m}$ phosphate buffer (PB), $\mathrm{pH}$ 7.3.

The brains were removed from the skull and cut into blocks. The blocks were then placed in a cryoprotective solution containing $10 \%$ glycerol and $2 \%$ dimethylsulphoxide (DMSO) in $0.1 \mathrm{M} \mathrm{PB}, \mathrm{pH} 7.3$, at $4{ }^{\circ} \mathrm{C}$. After 3 days, the blocks were transferred to a similar solution but with an increased concentration of glycerol (20\%) and incubated for four additional days according to the method of Rosene et al. (1986). The blocks were then frozen, cut into $30-\mu \mathrm{m}$-thick cross-sections, and stored in $0.1 \mathrm{M} \mathrm{PB}, \mathrm{pH}$ 7.3. In all experiments, one series of sections was stained with thionin for reference and two other series were submitted to HRP histochemistry using tetramethylbenzidine as chromogen (Mesulam, 1978, 1982). One of the HRP series was stained with $1 \%$ neutral red. In the fluorescent tracer experiments two series were collected for study and photodocumentation.

Two additional brainstems obtained from previously perfused animals and stored in buffered formalin were embedded in Paraplast, cut into 7- $\mu \mathrm{m}$-thick cross-sections and stained with thionin for cytoarchitectonic analysis.

\section{Nomenclature}

To facilitate comparisons between the monkey and human brain, the structures related to the 7Mot are named according to the NeuroNames Brain Hierarchy and Template Atlas of the Macaque Brain (Bowden \& Martin, 1995; Martin \& Bowden, 1996).

\section{Data analysis}

All specimens were studied and photographed under an epifluorescence light microscope (Aristoplan, Leica Instruments) equipped with a digitizing system (Microscope Digitizer System MD3, Minnesota Datametrics Inc.) that captures the microscope stage movements and transforms them into cartesian $x$ and $y$ coordinates through readout heads coupled to a personal computer. The cytoarchitectonic limits of the 7 Mot and the retrogradely labelled motoneurons were plotted using 
appropriate software (MdPlot Digitizer, Minnesota Datametrics Inc.), and transferred to the CorelDRAW 10 software. In order to compare the size of functional columns of retrogradely labelled neurons in different animals, the data were normalized using the total length of the nucleus as $100 \%$ for each animal.

The thionin-stained sections were studied under a stereomicroscope (Citoval II, Carl Zeiss). The external limit of the section, of the 7 Mot and its subnuclei, and of the main surrounding elements were drawn using a camera lucida. The drawings were digitized with a table scanner and transferred to the CorelDRAW 10 software.

All line artwork was scaled down, arranged into plates and printed, without further alteration, on a highresolution (1200 dpi) laser printer.

\section{Results}

\section{Mot cytoarchitecture}

The 7Mot of capuchin monkeys was located in the ventrolateral portion of the brainstem and was easily distinguishable from the surrounding structures at the transition between the pons and medulla oblongata. It measured on average $1875 \mu \mathrm{m}$ along the rostrocaudal axis and extended from the caudal pole of the medial superior olivary nucleus to the inferior olivary complex (Fig. 1). Its widest cross-sectional diameter, on average $1730 \mu \mathrm{m}$, was found in the middle third.

In cross-section, the 7 Mot showed an ovoid to triangular shape with the long axis directed from the ventrolateral to the dorsomedial portion. The nucleus consisted of typical motoneurons (Fig. 2) grouped into

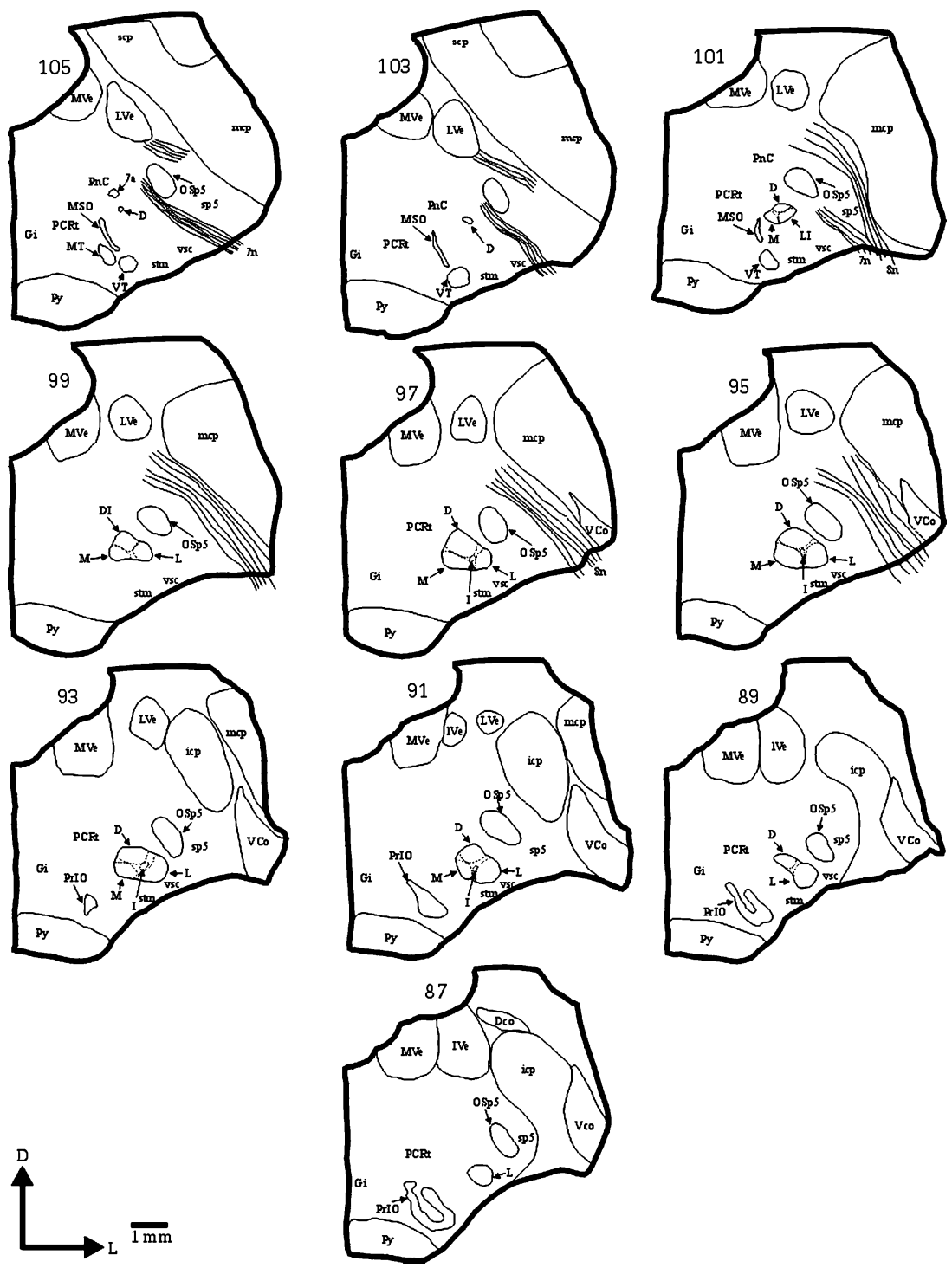

Fig. 1 Camera lucida drawings of the hemi-brainstem cross-sections of capuchin monkeys at the level of the 7 Mot. The sections were arranged from the rostral (section 105) to the caudal pole (section 87 ). The distance between serial sections is $180 \mu \mathrm{m}$. 7Mot subnuclei: $D$, dorsal subnucleus; $M$, medial subnucleus; $L$, lateral subnucleus. For other abbreviations, see list. 
Fig. 2 Photomicrographs of 7Mot crosssections. $A$ and $B$, motoneurons retrogradely labelled by HRP conjugate histochemistry and counterstained with neutral red. Injected muscles: $A$, zygomaticus; $B$, orbicularis oculi (superior portion). C, section stained with thionin showing three types of neurons: small arrowhead, round shape; large arrowhead, polygonal shape; arrow, spindle shape.
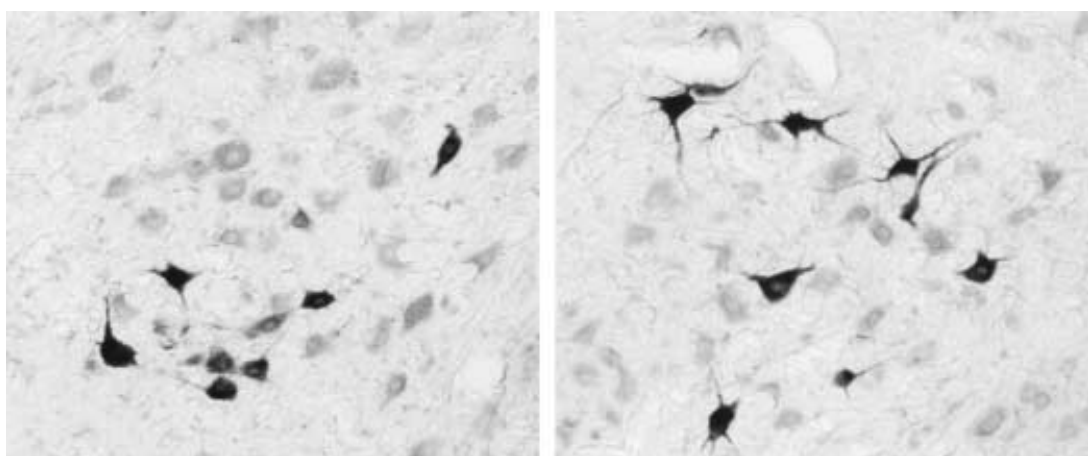

A

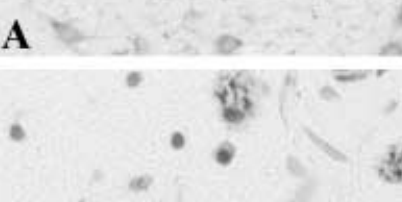

$100 \mu \mathrm{m} B$
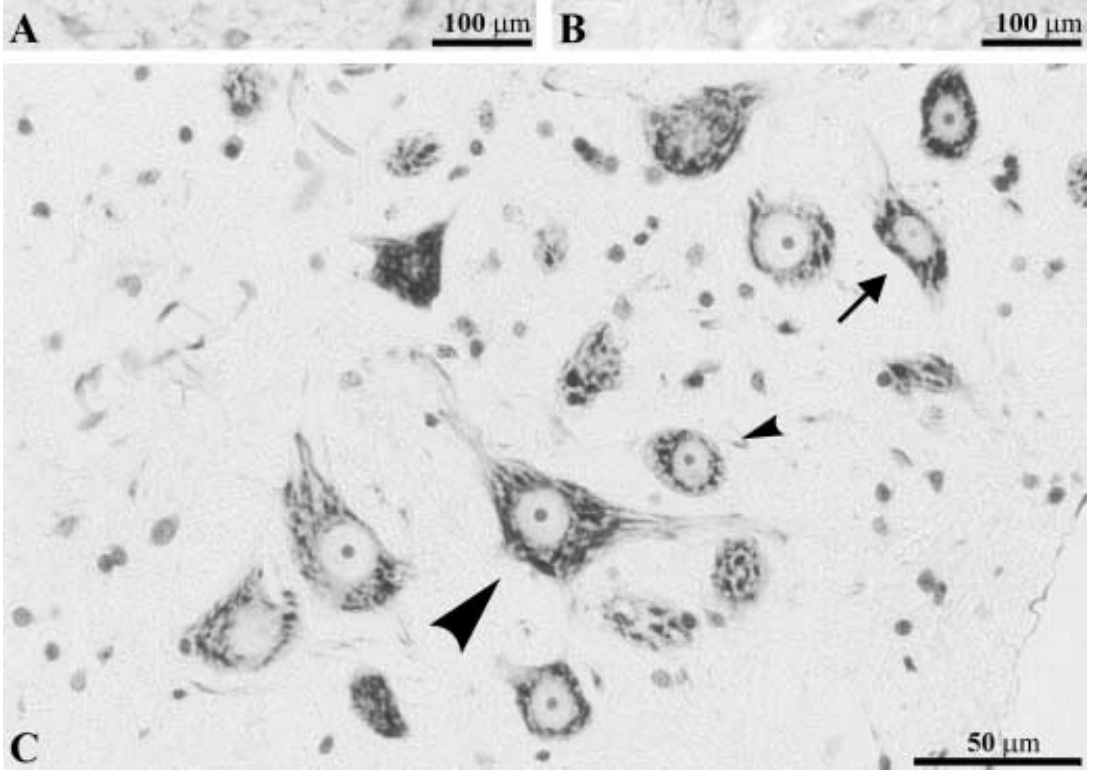

four longitudinally arranged subnuclei. Based on the nomenclature used in other studies, these subnuclei were designated as lateral, medial, dorsal and intermediate according to their position (Fig. 3).

The rostral pole of the 7Mot showed few, sometimes scattered cells that belonged to the dorsal subnucleus (Fig. 3A). At the rostral level, the intermediate subnucleus was generally fused to the dorsal subnucleus, which was the predominant nucleus. The other subnuclei could be identified in the middle third and all increased in size, reaching the largest area of the cross-section (Fig. 3D,E). The caudal pole was formed by a small group of large motoneurons that belonged to the lateral subnucleus (Fig. $3 \mathrm{H}$ ).

The clear individualization of the four subnuclei in a single section was only possible in the middle third. There was difficulty in individualizing the subnuclei at other levels owing to the presence of cellular groups that connect these subnuclei and to the disparity in the rostrocaudal length of each subnucleus, in addition to individual variations. The lateral subnucleus was the most evident because of its high neuronal density and because of the presence of a bundle of nervous tissue with few neurons, which separated this subnucleus from the other subnuclei. This bundle extended dorsoventrally and was interrupted, in some cases, by the intermediate subnucleus. Another bundle of nervous tissue with few neurons, although less evident, could be seen between the medial and dorsal subnuclei.

The intermediate subnucleus was the most difficult to individualize owing to its small size and position, which led to the fusion with larger subnuclei. In this case, the intermediate subnucleus was mainly fused to the dorsal subnucleus, which comprised its ventrolateral portion, although fusions with the lateral subnucleus were also frequent. In some cases, depending on the level of sectioning, fusion occurred between the dorsal, medial and intermediate subnuclei (Fig. 1).

The accessory facial nucleus was situated at the medial aspect of the descending root of the facial nerve dorsally 

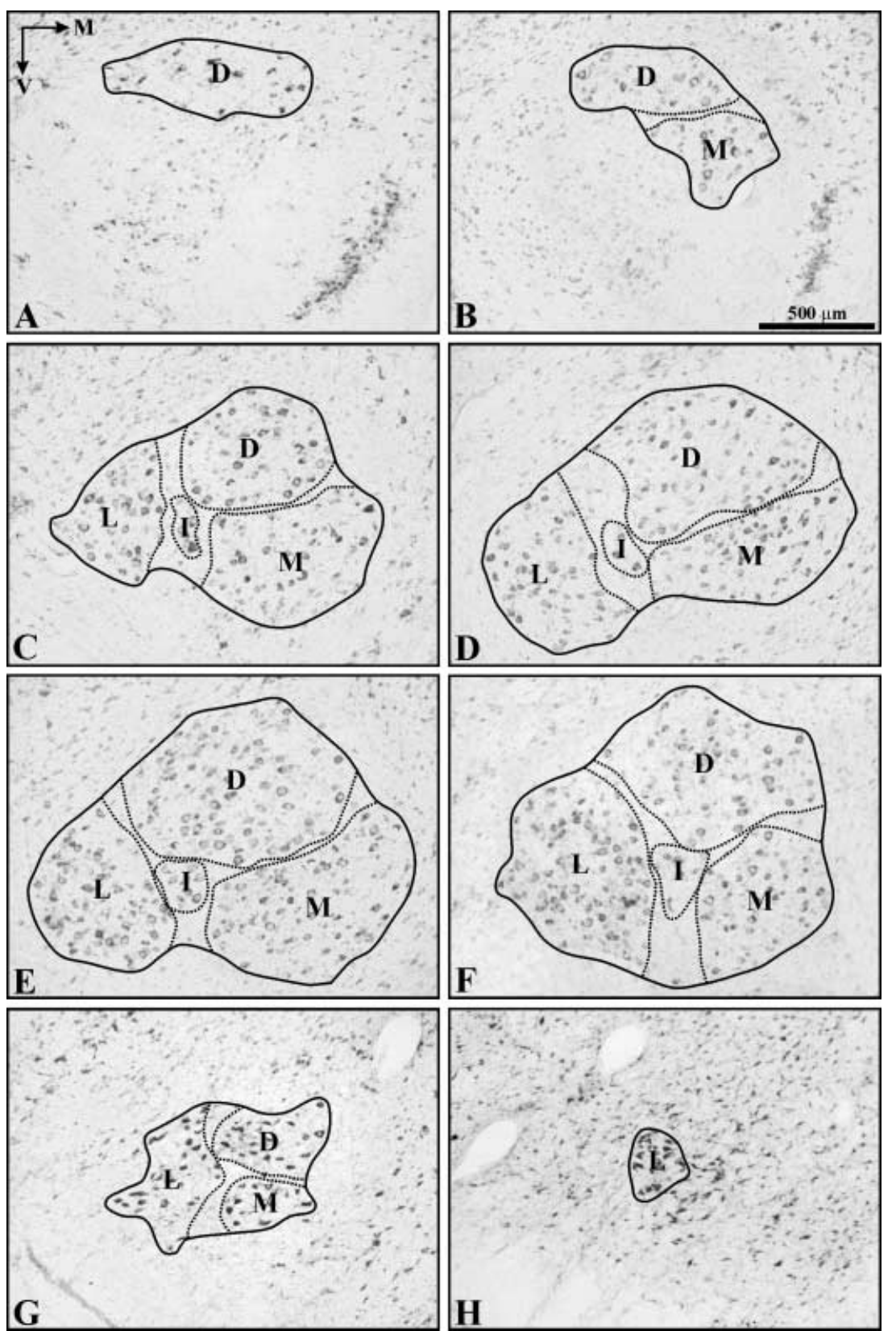

Fig. 3 Photomicrographs of 7Mot crosssections stained with thionin. The sections are shown in the rostrocaudal direction from $\mathrm{A}$ to $\mathrm{H}$. The continuous line delimits the 7Mot and the dotted line delimits the subnuclei, respectively, called: D, dorsal; M, medial; L, lateral; I, intermediate. The orientation arrows and the scale bar are valid for all photomicrographs.

and medially to the rostral pole of the 7Mot (7a in Fig. 1, section 105). As observed in cats and rabbits (Taber, 1961; Van Loveren et al. 1983; Davis \& Nail, 1984), the 7Mot continues caudally into the retrofacial nucleus, a rostral portion of the ambiguus nucleus (Taber, 1961).

\section{Mot musculotopic organization}

Injection of the neuroanatomical tracers into the muscles analysed resulted in the formation of columns of retrogradely labelled motoneurons in the 7 Mot. These functional columns extended rostrocaudally, sometimes in a discontinuous manner, with constant lateromedial and dorsoventral coordinates (Fig. 4). Groups of functionally related muscles showed adjacent or overlapping columns. For the muscles studied, the functional columns varied in rostrocaudal length from 58.4 to 95\% of the total 7Mot length (Fig. 5 and Table 2). It was possible to correlate one functional column with a given cytoarchitectonic subnucleus, except in the case of the frontalis and levator labii superioris alaeque nasi (LELSAN) muscles, whose functional columns occupied more than one cytoarchitectonic subnucleus. No cells were labelled in other brainstem nuclei, indicating that 

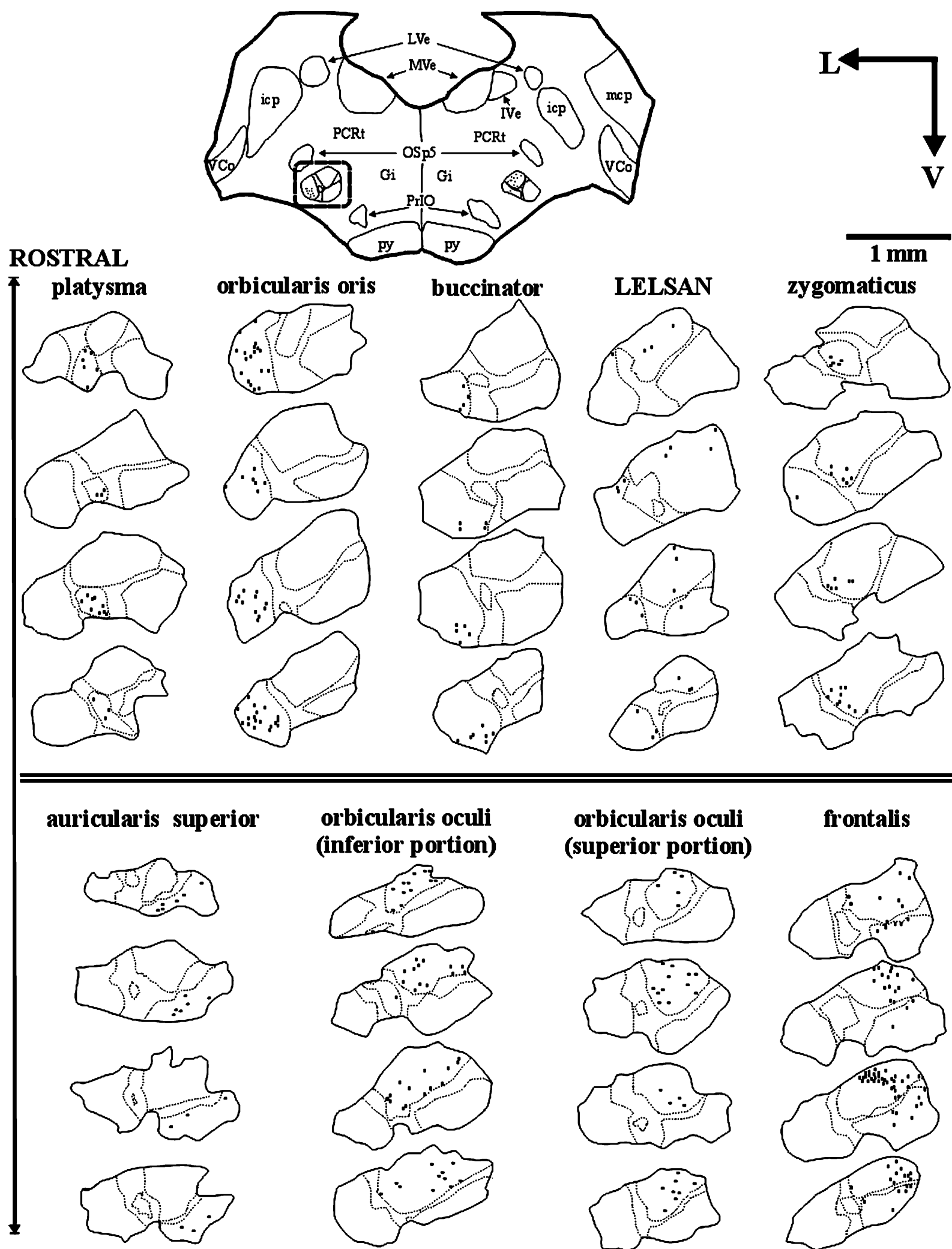
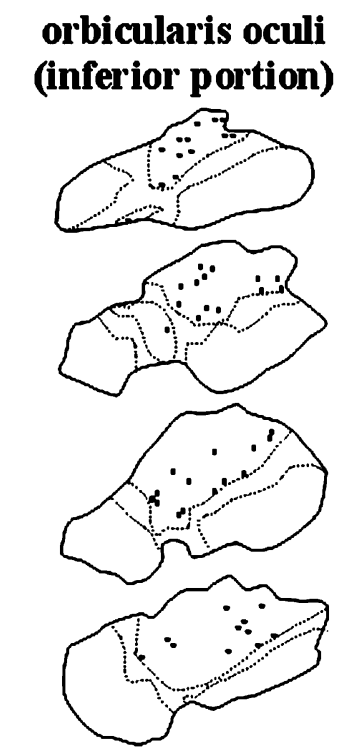
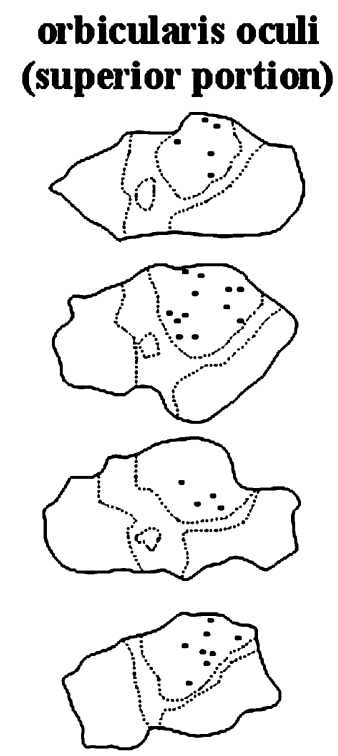

\section{CAUDAL}

Fig. 4 Plotted drawings of cross-sections of the 7Mot (highlighted on the left side of the cross-section drawing of the brainstem, at the top). Each injected muscle corresponds to one column. Dots indicate retrogradely labelled motoneurons after injection of the HRP conjugate into each muscle. The continuous line indicates the external limit of the nucleus and the dotted line the visible limit between subnuclei. The scale bar and the orientation arrows are valid for all columns. 
Table 2 Characteristics of the functional columns of motoneurons retrogradely labelled with HRP conjugates

\begin{tabular}{|c|c|c|c|c|c|c|}
\hline Animal & Side - Muscle & $\begin{array}{l}\text { Length of } \\
7 \text { Mot }(\mu \mathrm{m})\end{array}$ & $\begin{array}{l}\text { Labelled } \\
\text { length }(\mu \mathrm{m})\end{array}$ & Subnucleus & $\begin{array}{l}\text { Distance from } \\
\text { the rostral } \\
\text { pole }(\mu \mathrm{m})\end{array}$ & $\begin{array}{l}\text { Distance from } \\
\text { the caudal } \\
\text { pole }(\mu \mathrm{m})\end{array}$ \\
\hline \multirow[t]{2}{*}{ M8 } & $\mathrm{L}$ - orbicularis oculi (superior portion) & 1800 & 1200 & dorsal & 300 & 300 \\
\hline & $\mathrm{R}$ - auricularis superior & 1950 & 1500 & medial & 300 & 150 \\
\hline \multirow[t]{2}{*}{ M9 } & $\mathrm{L}-$ zygomaticus & 1800 & 1050 & intermediate & 600 & 150 \\
\hline & $\mathrm{R}$ - orbicularis oculi (inferior portion) & 1950 & 1500 & dorsal & 300 & 150 \\
\hline \multirow[t]{2}{*}{ M11 } & L - LELSAN & 1710 & 1350 & dorsal, medial and lateral & 360 & 0 \\
\hline & $\mathrm{R}$ - orbicularis oris & 1620 & 1440 & lateral & 180 & 0 \\
\hline \multirow[t]{2}{*}{ M12 } & $\mathrm{L}$ - frontalis & 2160 & 1890 & dorsal and medial & 90 & 180 \\
\hline & $\mathrm{R}$ - buccinator & 1800 & 1620 & lateral & 180 & 0 \\
\hline \multirow[t]{2}{*}{ M14 } & $\mathrm{L}-$ platysma & 1800 & 1710 & intermediate & 0 & 90 \\
\hline & $\mathrm{R}$ - frontalis & 1620 & 1170 & dorsal and medial & 180 & 270 \\
\hline
\end{tabular}

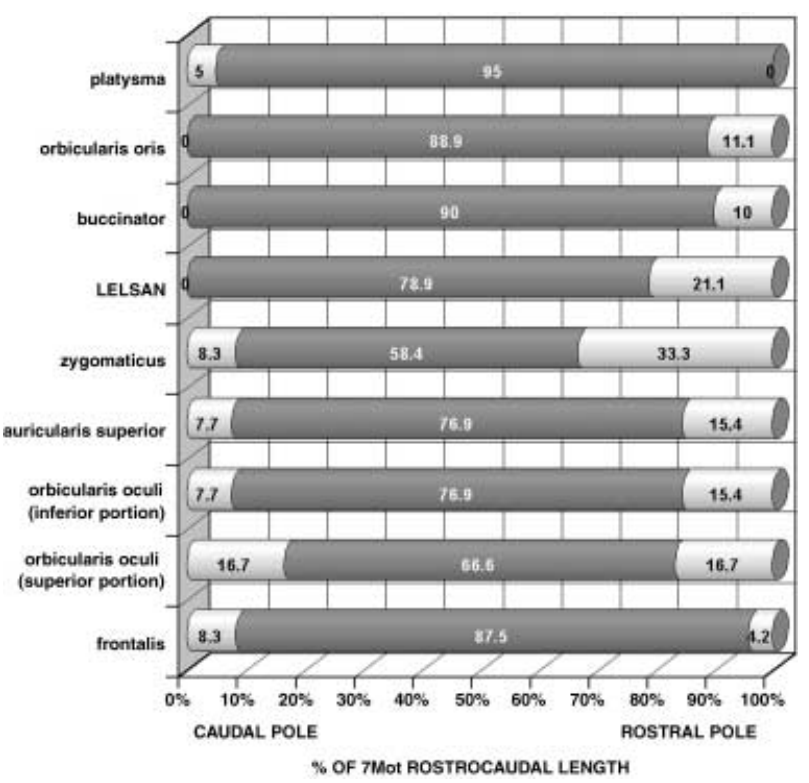

Fig. 5 Rostrocaudal distribution of the functional cell columns retrogradely labelled after injection of the HRP conjugate into the facial expression muscles studied. The dark portion of the bars indicates the functional column of labelled cells and the bright portions correspond to the remaining 7 Mot. The percentages indicate the length of the columns in relation to the total rostrocaudal length of the 7 Mot $(100 \%)$. The data regarding the frontalis muscle were obtained from case M12.

there had been no spread of neuroanatomical tracers into the surrounding facial structures.

The functional columns of the zygomaticus and platysma muscles were found to be located in the intermediate subnucleus (Fig. 4). The column of the platysma muscle was the most ventral and longest of all (Figs 5 and $6 \mathrm{~A}$ ). The column of the zygomaticus muscle, with the smallest rostrocaudal length, showed a larger number of retrogradely labelled motoneurons at more caudal levels (Figs 4, 5, 6D and 7D).
The functional columns of the orbicularis oris and buccinator muscles were located in the lateral subnucleus. The motoneurons responsible for the innervation of the superior and inferior portion of the orbicular oris muscle belonged to the same functional column and no separation between them was noted (Figs 4 and $6 \mathrm{~B})$. The column of the buccinator muscle was positioned ventromedially to that of the orbicular muscle and showed a larger number of motoneurons in the caudal half (Figs 4 and $6 \mathrm{C}$ ). The functional columns of these two muscles formed the caudal pole of the 7 Mot and extended until the vicinity of the rostral pole (Fig. 5 and Table 2).

The functional column of the orbicularis oculi muscle was located in the dorsal subnucleus irrespective of the muscle portion evaluated, i.e. superior or inferior. Therefore, the representation of the different portions of the same muscle overlapped in the same way as observed for the orbicularis oris (Figs 4, 6F, G and 7C).

The superior auricular muscle was chosen as representative of the auricular region owing to easy access and its relatively isolated position. After injection of the tracer into this muscle, a column consisting of few retrogradely labelled motoneurons was observed, which extended through three-quarters of the rostrocaudal length of the 7Mot and occupied the medial subnucleus (Figs 4, 5 and $6 \mathrm{E}$ ). The functional column of the frontalis muscle was found to be extended over a large part of the rostrocaudal length of the nucleus, mainly occupying the dorsal subnucleus but also the medial subnucleus, where the number of retrogradely labelled motoneurons was smaller (Figs 4, 5, and 6H). This column showed the largest number of retrogradely labelled neurons, preferentially positioned in the caudal half. This labelling pattern was confirmed in three 
Fig. 6 Photomicrographs of 7Mot cross-sections showing motoneurons retrogradely labelled with HRP conjugate and counterstained with neutral red. Injected muscles: $A$, platysma; B, orbicularis oris; $C$, buccinator; $D$, zygomaticus; $E$, auricularis superior; $F$, orbicularis oculi (inferior portion); G, orbicularis oculi (superior portion); $\mathrm{H}$, frontalis. The orientation arrows and the scale bar are valid for all photomicrographs.
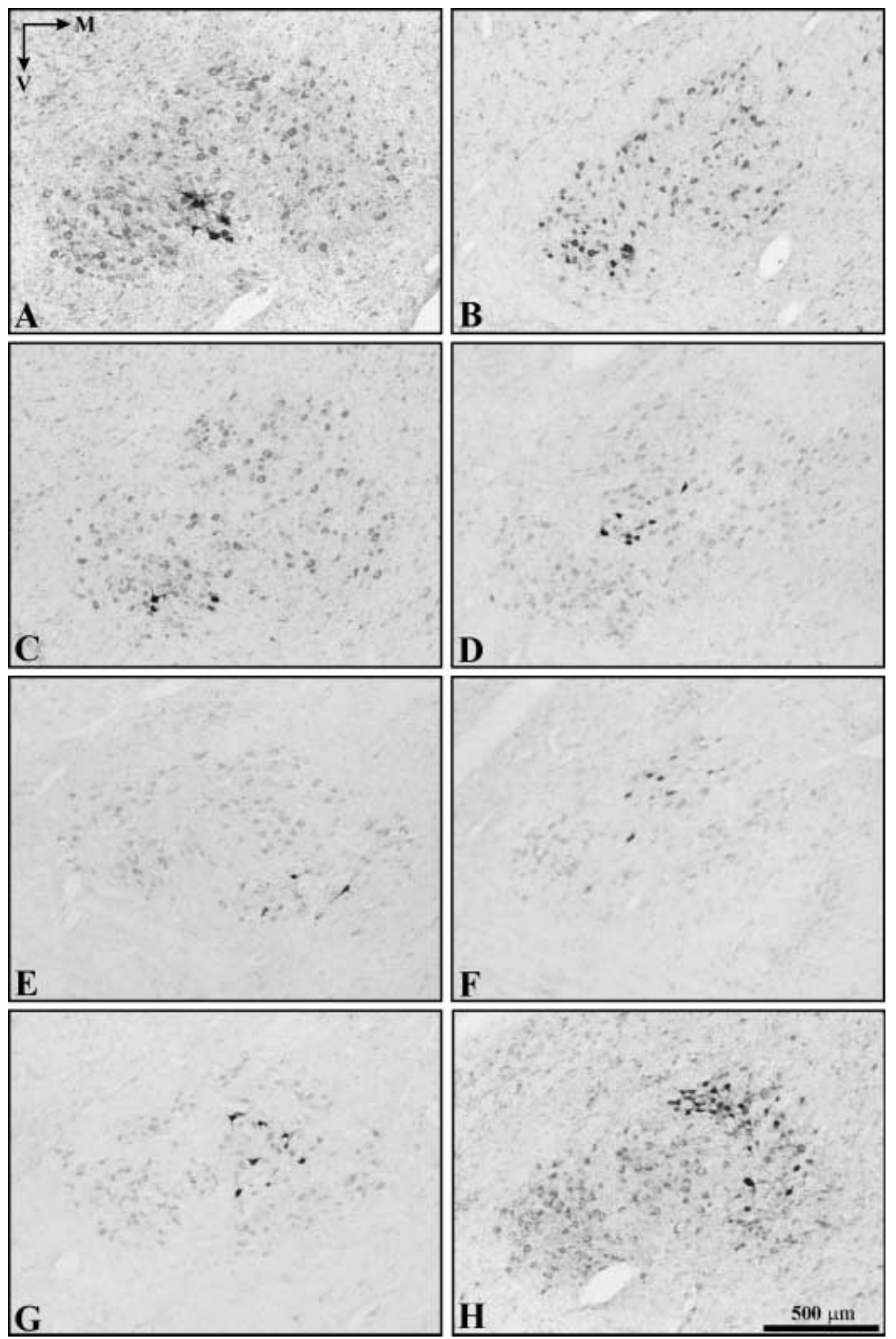

experiments using different types and quantities of the tracer, thus excluding the possibility of a technical artefact (Table 1). After injection of the neuroanatomical tracer into the LELSAN, retrogradely labelled motoneurons were observed in the dorsal subnucleus, dorsomedial portion of the lateral subnucleus and, occasionally, in the laterodorsal portion of the medial subnucleus (Fig. 4). In this muscle, we reduced as much as possible the amount of tracer injected in order to minimize diffusion.

The multiple labelling experiments using fluorescent retrograde tracers confirmed the musculotopic pattern described above, although a smaller number of retro- gradely labelled motoneurons was observed compared with the HRP conjugate experiments. No double-labelled neurons were detected (Fig. 7). It should be emphasized that we did not find the 'aberrant' motoneurons described for the motor nucleus of the trigeminal nerve (Mizuno et al. 1981; Jacquin et al. 1983; Lynch, 1985). These 'aberrant' cells are displaced motoneurons of one muscle found in the pool of another or in overlapping regions between two subnuclei. Displaced motoneurons may have axons that bifurcate into two or more muscles, with obvious functional implications. In the case of the Cebus facial motor system, our HRP conjugate 

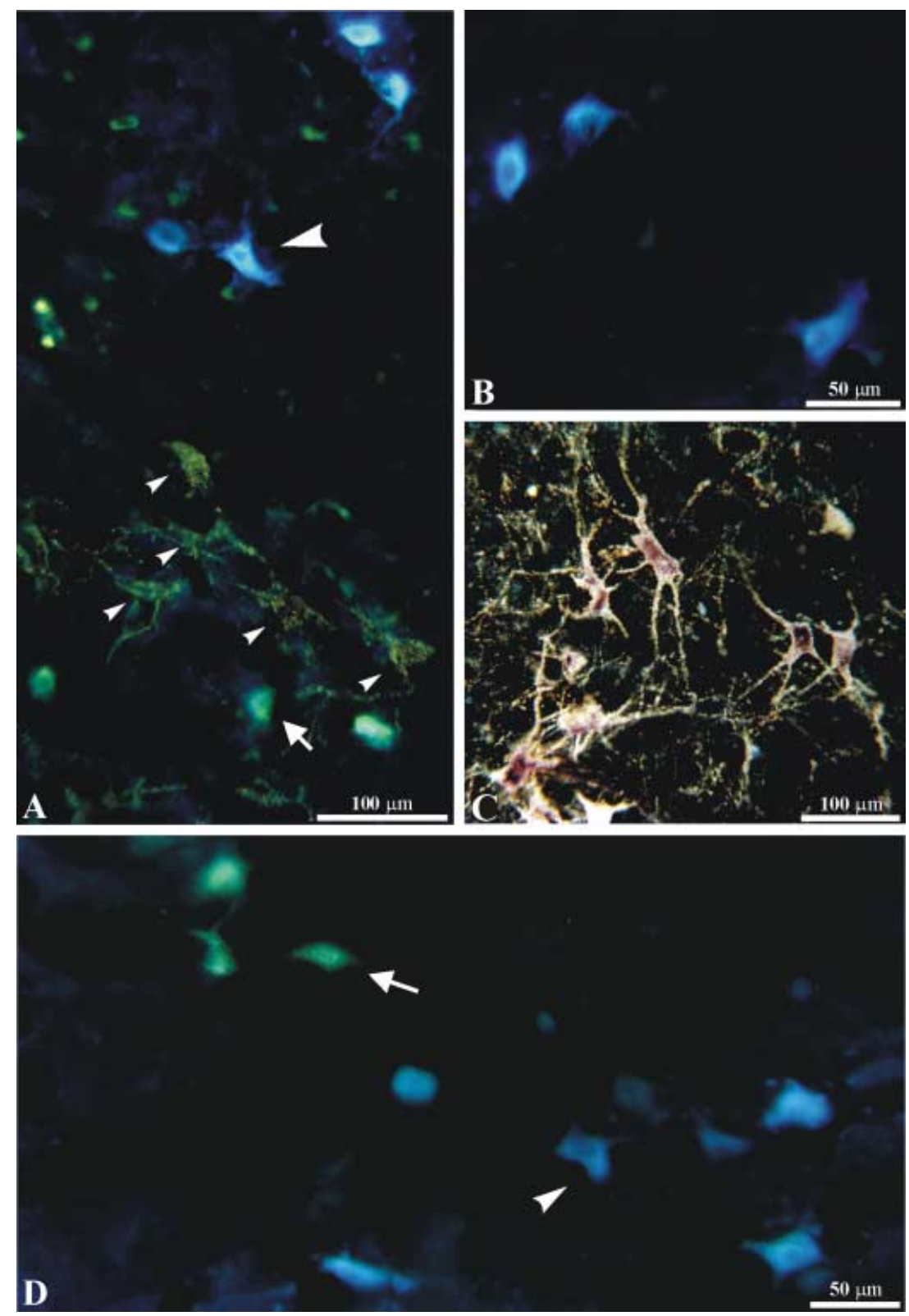

Fig. 7 Multiple labelling experiments. Three neuroanatomical tracers were injected into different muscles of the same side of the face. A, photomicrograph obtained by simultaneous dark-field illumination and epifluorescence. Large arrowhead, retrogradely labelled neuron after injection of Fast blue (FB) into the LELSAN; small arrowhead, retrogradely labelled neurons after injection of CTB-HRP into the auricularis superior; arrow, retrogradely labelled neuron after injection of Diamidino yellow (DY) into the frontalis. B, epifluorescence photomicrograph showing retrogradely labelled neurons after injection of FB into the LELSAN. C, dark-field photomicrograph showing retrogradely labelled neurons and their dendritic arborization after injection of CTB-HRP into the orbicularis oculi (superior portion). D, epifluorescence photomicrograph showing retrogradely labelled neurons after injection of DY (arrow) into the zygomaticus and of FB (arrowhead) into the orbicularis oris (inferior portion). experiments indicate that the 7Mot subnuclei appear as partly discrete entities, without the overlapping observed in the trigeminal motor system. Although further multiple labelling experiments are necessary, the absence of double-labelled neurons observed in the present study also seems to indicate the lack of axonal bifurcation.

\section{Discussion}

In the present study we describe the architecture and musculotopic organization of the facial motor nucleus in the Cebus apella monkey, a New World primate, which possesses a very rich repertoire of vocalization and facial expression (Weigel, 1979). We observed some particularities in terms of the relative size of each subnucleus and functional columns of the 7 Mot in C. apella, which might be related to the functional and behavioral importance of each muscle in the particular context of this primate.

Based on the present results, a general principle of musculotopic organization can be established for $C$. apella, superimposing the facial profile of this monkey on a cross-section of the 7Mot in such a way that the muscles arranged anteroposteriorly in the face are positioned lateromedially in the nucleus and the muscles arranged 


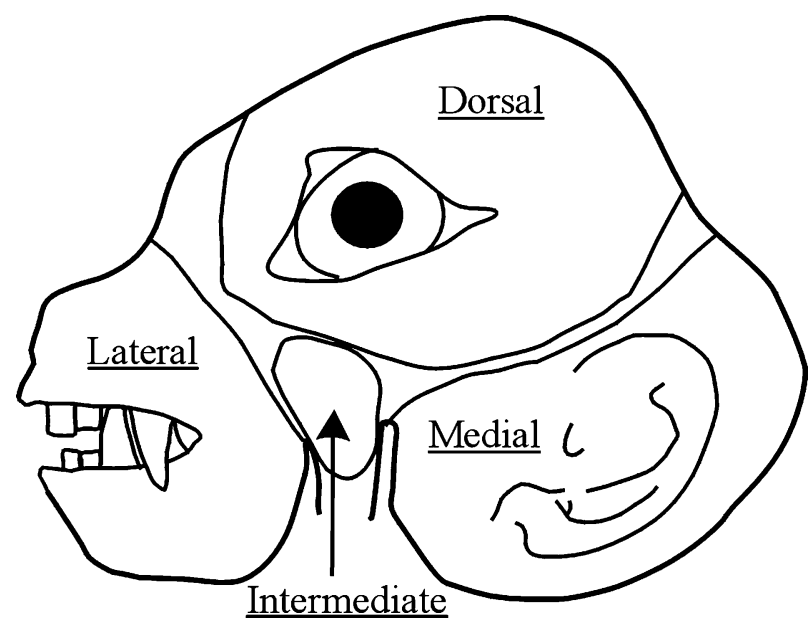

Fig. 8 Musculotopic representation of facial expression muscles in Cebus apella. The distorted face of the capuchin monkey corresponds to the external contour of the $7 \mathrm{Mot}$ in a histological cross-section comprising the middle third of the nucleus. The muscles arranged anteroposteriorly in the face are positioned lateromedially in the nucleus and the muscles arranged dorsoventrally in the face maintain the same dorsoventral arrangement in the nucleus. The subnuclei are delimited and named.

dorsoventrally in the face maintain the same dorsoventral arrangement in the nucleus (Fig. 8).

As reported in previous studies (Radpour, 1977; Radpour \& Gacek, 1980; Shaw \& Baker, 1985; Welt \& Abbs, 1990), regardless of whether the tracer was injected throughout the whole surface of the muscle or only into part of it, the entire functional column corresponding to this muscle was labelled, with variations being observed only in the number of labelled cells but not in the position or length of the functional column.

\section{Cytoarchitecture}

The present cytoarchitectonic study revealed similarities between the 7 Mot of primates and the facial motor nucleus of other species, except for a mild rotation of the nucleus as also observed in humans (Van Buskirk, 1945). The criterion for the subdivision of the 7 Mot was the same as that used in previous studies (Courville, 1966; Jenny \& Saper, 1987; Prats-Galino et al. 1988), which recognized areas of higher or lower neuronal density eventually separated by cell-poor bundles. We divided the C. apella 7Mot into four subnuclei, i.e. lateral, intermediate, medial and dorsal. This subdivision is similar to that reported for cats (Papez, 1927), dogs (Vraa-Jensen, 1942) and Old World monkeys (Jenny \&
Saper, 1987), but shows an increased dorsal subnucleus and reduced intermediate and medial subnuclei.

Individualization of the 7Mot subnuclei was fundamentally possible in the middle third of the nucleus. Partial fusion of the subnuclei at other levels has also been reported for dogs, humans (Van Buskirk, 1945) and monkeys (Welt \& Abbs, 1990). Despite the difficulty in subnucleus individualization, the lateral subnucleus could be easily distinguished from the other nuclei based on the presence of a poorly cellular nervous tissue bundle, which separated this subnucleus from the other subnuclei (Fig. 3). This characteristic has been previously described in cats by Shaw \& Baker (1985).

Our results show that the caudal pole of the 7 Mot is formed by the lateral subnucleus (Fig. $3 \mathrm{H}$ ), in agreement with observations made in Macaca fascicularis (Welt \& Abbs, 1990) and humans (Van Buskirk, 1945). In the cat and dog, the caudal pole is formed by subnuclei from the lateral and dorsal region of the 7Mot (Van Buskirk, 1945; Prats-Galino et al. 1988).

The rostral pole of the 7Mot of capuchin monkeys is made up of the dorsal subnucleus, as also observed in other monkeys and in dogs (Jenny \& Saper, 1987; PratsGalino et al. 1988; Welt \& Abbs, 1990). In humans, the rostral pole is formed by fusion of the dorsal, medial and intermediate subnuclei (Van Buskirk, 1945).

In studies conducted on non-human primates (Jenny \& Saper, 1987; Satoda et al. 1987; Welt \& Abbs, 1990) and humans (Van Buskirk, 1945; Pearson, 1946), the lateral subnucleus was the most developed of all subnuclei. However, in capuchin monkeys, the lateral subnucleus shared this position with the also highly developed dorsal subnucleus (Fig. 3).

With respect to the rostrocaudal length of the 7Mot in C. apella, our results agree with those reported for M. fascicularis (Jenny \& Saper, 1987; Welt \& Abbs, 1990), but disagree with those described by Welt \& Abbs (1990) in terms of the number of subnuclei. This difference might be due to the cytoarchitectonic criterion used by these authors, which took into account neuronal size.

\section{Musculotopic organization}

Our results indicate a clear musculotopic organization in the 7Mot, with individual muscles being innervated by longitudinal functional columns of motoneurons. This pattern resembles those obtained in studies carried out on other species and therefore represents a general pattern among various mammalian species. 
Our results confirm the existence of only one functional column of the orbicularis oculi muscle, as also observed for the orbicularis oris, confirming previous results obtained in rabbits (Shaw \& Baker, 1985) and primates (Welt \& Abbs, 1990).

All the labelled neurons were located in the $7 \mathrm{Mot}$ (Fig. 6). The absence of labelled cells in other brainstem motor nuclei is an adequate indication of the precision of our neuroanatomical tracer injections. Only in one experiment did we find a few labelled neurons in the trigeminal motor nucleus. According to musculotopic studies involving masticatory muscles (Mizuno et al. 1981; Jacquin et al. 1983), the retrogradely labelled neurons observed were located in the representation zone of the temporal muscle. This finding can be explained by the fact that in this case the neuroanatomical tracer was injected into the superior auricular muscle, which shows a direct topographical relationship with the temporal muscle.

The functional column of the platysma muscle was more extensive in C. apella than in M. fascicularis, a finding probably related to the functional attributions of the platysma muscle, which replaces the missing mentalis muscle in C. apella (Niccoli-Filho et al. 1986). The mentalis muscle is present in M. fascicularis and shows an extensive functional column (Welt \& Abbs, 1990).

Scattered labelled neurons were observed after injection of the tracer into the LELSAN (Fig. 4), with few labelled cells being found scattered in the dorsal subnucleus, lateral subnucleus (dorsomedial portion) and medial subnucleus (laterodorsal portion). Based on the distribution of the functional columns of the neighboring muscles, two hypotheses can be formulated: (1) the tracer diffused to the orbicularis oculi, orbicularis oris or maxillonasalis muscle with which the LELSAN maintains an intimate relationship (Niccoli-Filho et al. 1986); (2) the extremely thin, functional column of this muscle is distributed within different subnuclei. Unfortunately, no data are available in the literature to compare our results.

In the present study, no retrogradely labelled cells were observed in the mesencephalic trigeminal nucleus. This fact might be related to the apparent absence of muscle spindles in the facial musculature of monkeys (Sufit et al. 1984), or to the inability of the neuroanatomical tracer to reveal effectively the proprioceptive innervation. The latter possibility is highly unlikely because different types of neuroanatomical tracers were used, which, when injected into the trigeminal musculature, caused efficient labelling of the mesencephalic trigeminal nucleus (Jacquin et al. 1983). In addition, previous studies have indicated that the proprioceptive mechanisms in the facial musculature are related to the activation of skin mechanoreceptors (Lindquist, 1970).

Differences were observed between the present results and those obtained in studies in which the tracer was directly injected into the branches of the facial nerve (Jenny \& Saper, 1987; Satoda et al. 1987; Tsai et al. 1993). However, if we interpret the group of retrogradely labelled cells obtained after application of the tracer to one nervous branch as the sum of functional motoneuron columns of the muscles innervated by this branch, similarities between the results are noted. In fact, a more scattered labelling was observed when the tracer was applied to one branch of the facial nerve than when it was injected into an individual muscle (Tsai et al. 1993).

\section{Relationship between cytoarchitecture, musculotopic organization and ontogenetic perspective}

Despite the existence of an interspecies-specific general pattern of musculotopic organization for the 7Mot, comparison of the results was sometimes difficult owing to differences in the cytoarchitectonic subdivisions of the 7 Mot and the lack of uniformity in the terminology used to describe them. The variations in the architectonic pattern among different species are mainly due to the relative size of each subnucleus. This aspect seems to suffer functional influences, reflecting behavioral adaptation and the particular importance of the muscles of facial expression for the individual (Courville, 1966; Kume et al. 1978; Friauf \& Herbert, 1985; Semba \& Egger, 1986; Satoda et al. 1987). For example, the medial subnucleus, in which the functional column of the muscles related to the ear is found, shows a similar location in all mammals studied thus far. However, in animals in which ear movement is more important from a functional viewpoint, such as bats, cats and dogs, the medial subnucleus is larger than in other animals (Van Buskirk, 1945; Friauf \& Herbert, 1985). Likewise, the nuclear representation of the perioral musculature is proportionally larger in species in which the snout (due to movement of the vibrissae) or mouth (due to facial expression and vocalization) became functionally important structures (Dubner et al. 1978; Jenny \& Saper, 1987; Satoda et al. 1987). This principle of organization 
is also maintained in humans, in which the muscles of facial expression reached the highest degree of development, permitting the occurrence of elaborate facial expressions and more complex vocalizations. In C. apella, the functional column related to the frontalis muscle showed the largest number of retrogradely labelled neurons regardless of whether a larger (case M12, Table 1) or smaller (case M14) volume of the tracer was injected. Thus, the representation of the frontalis muscle is greater in capuchin monkeys than in other species and even than in M. fascicularis (Welt \& Abbs, 1990). This particularity of $C$. apella is probably related to the constant elevation of the forehead and supercilia during facial expression, which is not common among other primates or within the same genus (Weigel, 1979; Freese \& Oppenheimer, 1981).

From an ontogenetic perspective, the musculotopic organization of the 7 Mot that emerged in this study does not seem to confirm the ontogeny of the facial musculature described for other species (Provis, 1977; Hinrichsen \& Watson, 1984; Baisden et al. 1987). According to these studies, the 7 Mot is organized in such a way that the muscles derived from the sphincter colli profundus are represented laterally and those derived from the platysma layer are represented medially. In C. apella, the functional columns of the auricularis superior and frontalis muscles, derived from the sphincter colli profundus (Huber \& Hughson, 1926; Huber, 1961), lie in the medial subnucleus (Fig. 4). In addition, the neurons that innervate the platysma muscle, derived from the platysma layer, are located in the intermediate subnucleus. Previous studies have indicated that, although ontogenetic and phylogenetic factors provide an initial general position in relation to the motor nuclei and subnuclei, environmental factors (Moody \& Heaton, 1983a,b,c; Studer, 2001) and molecular signalling between neuroblasts and their targets during the initial stages of development seem to be decisive for the final morphology and position of the motoneurons (Ashwell \& Watson, 1983; Goffinet, 1990; Brennan et al. 1996; Widmer et al. 1998).

On the other hand, our results support the hypothesis raised for humans by Jacobs (1970) and Brown (1990) that those neuroblasts that first complete their differentiation and cease migration are the first to become functional. The migration of facial neuroblasts in the midline neuroepithelium occurs along a diagonal axis from the rostral dorsomedial to the caudal ventrolateral position (Jacobs, 1970; Auclair et al. 1996;
Swanson et al. 1999). Therefore, we may expect to find that groups of motoneurons, which differentiate and become functional at different times, are arranged along this migration axis. In the fetus, the first reflexes involving the musculature innervated by the facial nerve are related to the posterior venter of the digastric muscle, followed by those related to the orbicularis oculi and orbicularis oris muscles (Dubner et al. 1978). In C. apella, the accessory facial nucleus is found at a dorsomedial position in relation to the rostral pole of the 7Mot. This nucleus is responsible for the innervation of the posterior venter of the digastric muscle (Szentágothai, 1948; Matsuda et al. 1979; Shohara \& Sakai, 1983; Komiyama et al. 1984; Semba \& Egger, 1986; Uemura-Sumi et al. 1991). The dorsal subnucleus, which harbours the functional column of the orbicularis oculi, is located ventrolaterally to the accessory facial nucleus, following this hypothetical diagonal axis. Finally, the subnucleus that harbours the column of the orbicularis oris occupies a more ventrolateral position, a fact that agrees with the later occurrence of reflexes related to the perioral musculature (Jacobs, 1970; Dubner et al. 1978).

\section{Abbreviations in figures}

\begin{tabular}{|c|c|}
\hline 7a: & accessory facial nucleus \\
\hline 7n: & facial nerve \\
\hline 8n: & vestibulocochlear nerve \\
\hline CTB-HRP: & $\begin{array}{l}\text { horseradish peroxidase conjugated with } \\
\text { cholera toxin B subunit }\end{array}$ \\
\hline D: & dorsal subnucleus of facial motor nucleus \\
\hline DCo: & dorsal cochlear nucleus \\
\hline DI: & $\begin{array}{l}\text { intermediate subnucleus fusion with dorsal } \\
\text { subnucleus of facial motor nucleus }\end{array}$ \\
\hline DY: & diamidino yellow \\
\hline FB: & fast blue \\
\hline Gi: & gigantocellular nucleus \\
\hline HRP: & horseradish peroxidase \\
\hline I: & $\begin{array}{l}\text { intermediate subnucleus of facial motor } \\
\text { nucleus }\end{array}$ \\
\hline iсp: & inferior cerebellar peduncle \\
\hline IVe: & inferior vestibular nucleus \\
\hline L: & lateral subnucleus of facial motor nucleus \\
\hline LELSAN: & levator labii superioris alaeque nasi muscle \\
\hline LI: & $\begin{array}{l}\text { intermediate subnucleus fusion with lateral } \\
\text { subnucleus of facial motor nucleus }\end{array}$ \\
\hline LVe & lateral vestibular nucleus \\
\hline M: & medial subnucleus of facial motor nucleus \\
\hline
\end{tabular}


mcp: $\quad$ middle cerebellar peduncle

7Mot: $\quad$ facial motor nucleus

MSO: $\quad$ medial superior olivary nucleus

MVe: medial vestibular nucleus

OSp5: $\quad$ oral part of spinal trigeminal nucleus

PCRt: $\quad$ parvicellular reticular nucleus

PnC: $\quad$ caudal pontine reticular nucleus

PrIO: $\quad$ principal inferior olivary nucleus

py: $\quad$ pyramidal tract

scp: $\quad$ superior cerebellar peduncle

sp5: $\quad$ spinal trigeminal tract

stm: $\quad$ spinothalamic tract of medulla

Tz: $\quad$ trapezoid nuclei

VCo: ventral cochlear nuclei

VSc: ventral spinocerebellar tract

WGA-HRP: horseradish peroxidase conjugated with wheat germ agglutinin

\section{Acknowledgements}

We thank Dr José Américo Oliveira, head of the Capuchin Monkey Reproduction Center, School of Dentistry, UNESP, Araçatuba - SP, Brazil, for the donation of the animals studied, and Mr José Ari Gualberto Junqueira and Mr Arnaldo César dos Santos for help with animal handling and collection of the material. We are also grateful to Drs Jackson Cioni Bittencourt and Jair de Campos Soares for suggestions on the article. This research was supported by Conselho Nacional de Desenvolvimento Científico e Tecnológico (CNPq) Grant no. 130142/97-2.

\section{References}

Ashwell KW (1982) The adult mouse facial nerve nucleus: morphology and musculotopic organization. J. Anat. 135, 531-538.

Ashwell KW, Watson CR (1983) The development of facial motoneurones in the mouse neuronal death and the innervation of the facial muscles. J. Embryol. Exp. Morph. 77, 117-141.

Auclair F, Valdes N, Marchand R (1996) Rhombomere-specific origin of branchial and visceral motoneurons of the facial nerve in the rat embryo. J. Comp. Neurol. 369, 451-461.

Baisden RH, Woodruff ML, Whittington DL, Baker DC, Benson AE (1987) Cells of origin of the branches of the facial nerve: a retrograde HRP study in the rabbit. Am. J. Anat. 178, 175-184.

Bowden DM, Martin RF (1995) NeuroNames Brain Hierarchy. Neuroimage 2, 63-83.

Brennan TJ, Olson EN, Klein WH, Winslow JW (1996) Extensive motor neuron survival in the absence of secondary skeletal muscle fiber formation. J. Neurosci. Res. 45, 57-68.
Brown JW (1990) Prenatal development of the human nucleus ambiguus during the embryonic and early fetal periods. Am. J. Anat. 189, 267-283.

Cavada C, Huisman AM, Kuypers HG (1984) Retrograde double labeling of neurons: the combined use of horseradish peroxidase and diamidino yellow dihydrochloride (DY $X$, $2 \mathrm{HCl}$ ) compared with true blue and $\mathrm{DY} X, 2 \mathrm{HCl}$ in rat descending brainstem pathways. Brain Res. 308, 123-136.

Ciochon RL, Chiarelli AB (1980) Evolutionary Biology of the New World Monkeys and Continental Drift. New York: Plenum Press.

Committee on Guidelines for the Use of Animals in Neuroscience and Behavioral Research (2003) Guidelines for the Care and Use of Mammals in Neuroscience and Behavioral Research. Washington, DC: The National Academies Press.

Costa-Llobet C, Prats-Galino A, Arroyo-Guijarro J, Ruano-Gil D (1988) The facial motor nucleus of the dog. II. Morphometric analysis. Acta Anat. (Basel) 132, 280-283.

Courville J (1966) The nucleus of the facial nerve; the relation between cellular groups and peripheral branches of the nerve. Brain Res. 1, 338-354.

Davis PJ, Nail BS (1984) On the location and size of laryngeal motoneurons in the cat and rabbit. J. Comp. Neurol. 230, 13-32.

Dom R, Falls W, Martin GF (1973) The motor nucleus of the facial nerve in the opossum (Didelphis marsupialis virginiana). Its organization and connections. J. Comp. Neurol. 152, 373-401.

Dubner R, Sessle BJ, Storey AT (1978) Jaw, facial, and tongue reflexes. In The Neural Basis of Oral and Facial Function (eds Dubner R, Sessle BJ, Storey AT), pp. 280-290. New York: Plenum Press.

Freese CH, Oppenheimer JR (1981) The capuchin monkeys, genus Cebus. In Ecology and Behavior of Neotropical Primates (eds Coimbra-Filho AF, Mittermier RA), 1, pp. 331-90. Rio de Janeiro: Academia Brasileira de Ciências.

Friauf E, Herbert H (1985) Topographic organization of facial motoneurons to individual pinna muscles in rat (Rattus rattus) and bat (Rousettus aegypticus). J. Comp. Neurol. 240, 161-170.

Friauf E (1986) Morphology of motoneurons in different subdivisions of the rat facial nucleus stained intracellularly with horseradish peroxidase. J. Comp. Neurol. 253, 231241.

Goffinet AM (1990) Determinants of nerve cell patterns during development: a review. Eur. J. Morph. 28, 149-168.

Goodman M, Porter CA, Czelusniak J, Page SL, Schneider H, Shoshani J, et al. (1998) Toward a phylogenetic classification of primates based on DNA evidence complemented by fossil evidence. Mol. Phylogenet. Evol. 9, 585-598.

Hinrichsen CF, Watson CD (1984) The facial nucleus of the rat: representation of facial muscles revealed by retrograde transport of horseradish peroxidase. Anat. Rec. 209, 407-415.

Huber E, Hughson W (1926) Experimental studies on the voluntary motor innervation of the facial musculature. $J$. Comp. Neurol. 42, 113-163.

Huber E (1961) The facial musculature and its innervation. In The Anatomy of the Rhesus Monkey (eds Hartman CG, Straus-Junior WL), pp. 176-188. New York: Hafner. 
Jacobs MJ (1970) The development of the human motor trigeminal complex and accessory facial nucleus and their topographic relations with the facial and abducens nuclei. J. Comp. Neurol. 138, 161-194.

Jacquin MF, Rhoades RW, Enfiejian HL, Egger MD (1983) Organization and morphology of masticatory neurons in the rat: a retrograde HRP study. J. Comp. Neurol. 218, 239-256.

Jenny AB, Saper CB (1987) Organization of the facial nucleus and corticofacial projection in the monkey: a reconsideration of the upper motor neuron facial palsy. Neurology 37, 930-939.

Komiyama M, Shibata H, Suzuki T (1984) Somatotopic representation of facial muscles within the facial nucleus of the mouse. A study using the retrograde horseradish peroxidase and cell degeneration techniques. Brain Behav. Evol. 24, 144-151.

Kume M, Uemura M, Matsuda K, Matsushima R, Mizuno N (1978) Topographical representation of peripheral branches of the facial nerve within the facial nucleus: a HRP study in the cat. Neurosci. Lett. 8, 5-8.

Lindquist C (1970) Microelectrode recording from the facial nucleus in the cat. Acta Physiol. Scand. 80, 1A-2A.

Lynch R (1985) A qualitative investigation of the topographical representation of masticatory muscles within the motor trigeminal nucleus of the rat: a horseradish peroxidase study. Brain Res. 327, 354-358.

Martin MR, Lodge D (1977) Morphology of the facial nucleus of the rat. Brain Res. 123, 1-12.

Martin RF, Bowden DM (1996) A stereotaxic template atlas of the macaque brain for digital imaging and quantitative neuroanatomy. Neuroimage 4, 119-150.

Matsuda K, Uemura M, Takeuchi Y, Kume M, Matsushima R, Mizuno N (1979) Localization of motoneurons innervating the posterior belly of the digastric muscle: a comparative anatomical study by the HRP method. Neurosci. Lett. 12, 47-52.

Mesulam MM (1978) Tetramethyl benzidine for horseradish peroxidase neurohistochemistry: a non-carcinogenic blue reaction product with superior sensitivity for visualizing neural afferents and efferents. J. Histochem. Cytochem. 26, 106-117.

Mesulam MM (1982) Principles of horseradish peroxidase neurohistochemistry and their applications for tracing neural pathways - Axonal transport, enzyme histochemistry and light microscopic analysis. In Tracing Neuronal Connections with Horseradish Peroxidase (ed. Mesulam MM), pp. 1-151. New York: John Wiley and Sons.

Mizuno N, Matsuda K, Iwahori N, Uemura-Sumi M, Kume M, Matsushima R (1981) Representation of the masticatory muscles in the motor trigeminal nucleus of the macaque monkey. Neurosci. Lett. 21, 19-22.

Moody SA, Heaton MB (1983a) Developmental relationships between trigeminal ganglia and trigeminal motoneurons in chick embryos. I. Ganglion development is necessary for motoneuron migration. J. Comp. Neurol. 213, 327-343.

Moody SA, Heaton MB (1983b) Developmental relationships between trigeminal ganglia and trigeminal motoneurons in chick embryos. II. Ganglion axon ingrowth guides motoneuron migration. J. Comp. Neurol. 213, 344-349.
Moody SA, Heaton MB (1983c) Developmental relationships between trigeminal ganglia and trigeminal motoneurons in chick embryos. III. Ganglion perikarya direct motor axon growth in the periphery. J. Comp. Neurol. 213, 350-364.

Niccoli-Filho WD, Madeira MC, Oliveira JA, Simões S, Faig-Leite H (1986) Aspectos anatômicos dos músculos da expressão facial do macaco-prego (Cebus apella). Rev. Bras. Ciên. Morfol. 3, 12-17.

Oliveira JA, Niccoli-Filho WD, Faig-Leite H, Simões S, Madeira MC (1988) Aspectos anatômicos do nervo facial do macaco prego (Cebus apella). Rev. Brasil. Biol. 48, 785-788.

Papez JW (1927) Subdivisions of the facial nucleus. J. Comp. Neurol. 43, 159-191.

Pearson AA (1946) The development of the motor nuclei of the facial nerve in man. J. Comp. Neurol. 85, 461-476.

Prats-Galino A, Costa-Llobet C, Arroyo-Guijarro J, Ruano-Gil D (1988) The facial motor nucleus of the dog. I. Cytoarchitectonic subdivisions and cytology. Acta Anat. (Basel). 132, 276-279.

Provis J (1977) The organization of the facial nucleus of the brush-tailed possum (Trichosurus vulpecula). J. Comp. Neurol. 172, 177-188.

Radpour S (1977) Organization of the facial nerve nucleus in the cat. Laryngoscope 87, 557-574.

Radpour S, Gacek RR (1980) Facial nerve nucleus in the cat. Further study. Laryngoscope 90, 685-692.

Rosene DL, Roy NJ, Davis BJ (1986) A cryoprotection method that facilitates cutting frozen sections of whole monkey brains for histological and histochemical processing without freezing artifact. J. Histochem. Cytochem. 34, 1301-1315.

Satoda T, Takahashi O, Tashiro T, Matsushima R, UemuraSumi M, Mizuno N (1987) Representation of the main branches of the facial nerve within the facial nucleus of the Japanese monkey (Macaca fuscata). Neurosci. Lett. 78, 283-287.

Satoda T, Takahashi O, Tashiro T, Matsushima R, UemuraSumi M, Mizuno N (1988) Somatotopic organization of facial nucleus of rabbit. With particular reference to intranuclear representation of perioral branches of the facial nerve. Anat. Anz. 165, 83-90.

Schneider H, Canavez FC, Sampaio I, Moreira MA, Tagliaro CH, Seuanez HN (2001) Can molecular data place each neotropical monkey in its own branch? Chromosoma. 109, 515-23.

Semba K, Egger MD (1986) The facial 'motor' nerve of the rat: control of vibrissal movement and examination of motor and sensory components. J. Comp. Neurol. 247, 144-158.

Shaw MD, Baker R (1985) Morphology of motoneurons in a mixed motor pool of the cat facial nucleus that innervate orbicularis oculis and quadratus labii superioris, stained intracellularly with horseradish peroxidase. Neuroscience 14, 627-643.

Shohara E, Sakai A (1983) Localization of motoneurons innervating deep and superficial facial muscles in the rat: a horseradish peroxidase and electrophysiologic study. Exp. Neurol. 81, 14-33.

Studer M (2001) Initiation of facial motoneurone migration is dependent on rhombomeres 5 and 6. Development 128, 3707-3716.

Sufit RL, Poulsen G, Welt C, Abbs JH (1984) Morphology and histochemistry of the facial muscles of Macaca fascicularis. Soc. Neurosci. Abstract. 10, 779. 
Swanson JJ, Kuehl-Kovarik MC, Elmquist JK, Sakaguchi DS, Jacobson CD (1999) Development of the facial and hypoglossal motor nuclei in the neonatal Brazilian opossum brain. Brain Res. Dev. Brain Res. 112, 159-172.

Szentágothai J (1948) The representation of the facial and scalp muscles in the facial nucleus. J. Comp. Neurol. 88, 207-220.

Taber E (1961) The cytoarchitecture of the brain stem of the cat. 1. Brain stem nuclei of cat. J. Comp. Neurol. 116, 27-69.

Trojanowski JQ, Gonatas JO, Gonatas NK (1982) Horseradish peroxidase (HRP) conjugates of cholera toxin and lectins are more sensitive retrogradely transported markers than free HRP. Brain Res. 231, 33-50.

Tsai TC, Wu CH, Wen CY, Shieh JY (1993) Studies of the motoneurons following the injection of horseradish peroxidase into the peripheral branches of the facial nerve in rats. Acta Anat. (Basel) 148, 42-48.

Uemura-Sumi M, Satoda T, Tashiro T, Matsushima R, Mizuno $\mathbf{N}$ (1991) Re-examination of the topographical distribution of motoneurons innervating the digastric muscle in the rabbit and guinea pig. Anat. Anz. 173, 9-16.
Van Buskirk C (1945) The seventh nerve complex. J. Comp. Neurol. 82, 303-333.

Van Loveren H, Saunders MC, Keller JT (1983) Localization of motoneurons innervating the levator veli palatini muscle in the cat. Brain Res. Bull. 11, 303-307.

Vraa-Jensen G (1942) The Motor Nucleus of the Facial Nerve. Copenhagen: Ejnar Munksgaard.

Wan XC, Trojanowski JQ, Gonatas JO (1982) Cholera toxin and wheat germ agglutinin conjugates as neuroanatomical probes: their uptake and clearance, transganglionic and retrograde transport and sensitivity. Brain Res. 243, 215-224.

Weigel RM (1979) The facial expressions of the brown capuchin monkey (Cebus apella). Behaviour 68, 250-276.

Welt C, Abbs JH (1990) Musculotopic organization of the facial motor nucleus in Macaca fascicularis: a morphometric and retrograde tracing study with cholera toxin B-HRP. J. Comp. Neurol. 291, 621-636.

Widmer CG, Morris-Wiman JA, Calhoun JC (1998) Development of trigeminal mesencephalic and motor nuclei in relation to masseter muscle innervation in mice. Brain Res. Dev. Brain Res. 108, 1-11. 